\title{
Efektivitas Sumber Nutrisi Terhadap Pertumbuhan Beberapa Varietas Selada (Lactuca sativa L.) pada Sistem Hidroponik
}

\author{
Effectiveness of Nutrient Sources on the Growth of Several Varieties of Lettuce \\ (Lactuca sativa L.) in Hydroponic Systems \\ Ayu Soleha, Bejo Suroso, Insan Wijaya \\ Program Studi Agroteknologi, Faperta UM Jember, Jember \\ e-mail: bejo@unmuhjember.ac.id, insanwijaya@unmuhjember.ac.id
}

\begin{abstract}
ABSTRAK
Sayuran selada banyak digemari oleh masyarakat untuk dikonsumsi sebagai lalapan, penghias makanan. Seiring permintaan sayuran selada meningkat dan lahan pertanian beralih menjadi lahan non pertanian maka memanfaatkan lahan sempit untuk budidaya sayuran. Penelitian ini bertujuan untuk respon pertumbuhan beberapa varietas selada (Lactuca sativa L.) dan macam jenis nutrisi yang dibudidayakan pada sistem hidroponik. Penelitian ini menggunakan rancangan petak terbagi (Split plot design) yang terdiri dua faktor yaitu faktor pertama sebagai petak utama, jenis nutrisi (N) terdiri 3 taraf : N1 = AB Mix, N2 = POC Biogan, N3 = POP Supernasa sedangkan faktor kedua sebagai anak petak, varietas $(\mathrm{V})$ terdiri 3 taraf: $\mathrm{V} 1=$ Selada keriting, V2 = Selada merah, V3 = Selada krop masing - masing diulang tiga kali. Berdasarkan hasil penelitian menunjukkan bahwa perlakuan nutrisi AB Mix (N1) merupakan perlakuan terbaik karena berpengaruh nyata terhadap pertumbuhan tanaman selada. Sedangkan perlakuan varietas selada krop (V3) merupakan perlakuan terbaik karena berpengaruh nyata terhadap pertumbuhan selada diantaranya lebar daun, panjang daun, berat segar tanaman. Interaksi antara nutrisi dengan varietas berpengaruh nyata terhadap jumlah daun dan lebar daun (30 hst) sedangkan perlakuan lainnya tidak berpengaruh nyata.
\end{abstract}

Kata kunci : Varietas selada, Sumber nutrisi, Hidroponik

\section{ABSTRACT}

Lettuce is much loved by the community to be consumed as fresh vegetables, food decoration. As demand for lettuce increases and agricultural land is turned into non-agricultural land, making use of narrow land for vegetable cultivation. This study aims to respond to the growth of some varieties of lettuce (Lactuca sativa L.) and various types of nutrients that are cultivated in the hydroponic system. This study uses a split plot design which consists of two factors: the first factor is the main plot, the type of nutrition (N) consists of 3 levels: N1 = AB Mix, N2 = POC Biogan, N3 = POP Supernasa while the second factor is a child plot, variety $(V)$ consists of 3 levels: $V 1=$ curly lettuce, $V 2=$ red lettuce, $V 3=$ crop lettuce each repeated three times. Based on the results of the study showed that the nutritional treatment of AB Mix (N1) was the best treatment because it significantly affected the growth lettuce. While the treatment of crop lettuce varieties (V3) is the best treatment because it significantly influences the growth lettuce including leaf width, leaf length, plant fresh weight. The interaction between nutrition and variety has a significant effect on the number of leaves and leaf width (30 HST) while other treatments have no significant effect. fresh weight of the plant. The interaction between nutrition and variety has a significant effect on the number of leaves and leaf width (30 HST) while other treatments have no significant effect. fresh weight of the plant. The interaction between nutrition and variety has a significant effect on the number of leaves and leaf width (30 HST) while other treatments have no significant effect.

Keywords: Lettuce variety, Nutrition source, Hydroponics 


\section{PENDAHULUAN}

Selada merupakan tanaman sayuran yang banyak digemari oleh masyrakat karena memiliki sumber vitamin. Setiap tanaman selada memiliki warna daun yang beragam. Umumnya sayuran selada digunakan untuk pelengkap beberapa menu seperti penghias makanan, campuran kebab, dan hidangan lainnya.

Berdasarkan produksi sayuran selada di Indonesia pada tahun 2015 sampai 2017 menunjukkan sayuran selada pada tahun 2015 produksi sebesar 600.200 ton. Pada tahun 2016 produksi sayuran selada sebesar 601.204 ton dan tahun 2017 produksi sebesar 627.611 ton (BPS, 2017). Hal ini disebabkan kebutuhan akan komoditi selada semakin meningkat sejalan dengan perkembangan usaha tata boga, perhotelan serta tingkat kesadaran masyarakat akan pentingnya gizi.

Menurut data BPS (2015), terjadi kepadatan penduduk menurut provinsi di Indonesia pada tahun 2010 sebesar 124 juta jiwa, tahun 2013 sebesar 130 juta jiwa, tahun 132 juta jiwa, pada tahun 2015 sebesar 134 juta. Jumlah penduduk ini menjadikan sumber makanan semakin bertambah seiring dengan semakin besarnya konversi lahan pertanian ke lahan non pertanian. Hal ini memberikan kendala bagi kegiatan budidaya pertanian terutama dalam penyediaan lahan sehingga dalam mengatasi hal ini adalah dengan menggunakan sistem pertanian lahan sempit (Suhandoko $d k k, 2018$ ). Salah satu metode budidaya sayuran dalam mengatasi lahan sempit dengan cara sistem hidroponik. Hidroponik adalah lahan budidaya pertanian tanpa menggunakan media tanah sehingga hidroponik merupakan aktivitas pertanian yang dijalankan dengan menggunakan air sebagai medium untuk menggantikan tanah. Sistem bercocok tanam secara hidroponik dapat memanfaatkan lahan yang sempit (Roidah, 2015).

\section{METODE PENELITIAN}

Penelitian ini dilaksanakan di Kebun Percobaan (Green House) Fakultas Pertanian Muhammadiyah Jember yang bertempat di jalan karimata 49, Kecamatan Sumbersari Kabupaten Jember. Pelaksanaan Penelitian dimulai pada bulan Desember 2019 sampai Februari 2020 dengan ketinggian tempat 89 di atas permukaan laut (dpl). penelitian ini menggunakan rancangan split plot (RAL) terdiri dari dua faktor yaitu faktor pertama sebagai petak utama, (N1) AB Mix, (N2) POC Biogan, (N3) POP Supernasa dan faktor kedua sebagai anak petak, (V1) Selada keriting, (V2) Selada merah, (V3) Selada krop keduanya diulang tiga kali. 


\section{PEMBAHASAN}

\section{Tinggi tanaman}

Tabel 1. Rerata tinggi tanaman yang dipengaruhi oleh perlakuan nutrisi semua umur tanaman.

\begin{tabular}{lccc}
\hline \multirow{2}{*}{\multicolumn{1}{c}{ Nutrisi }} & \multicolumn{3}{c}{ Tinggi tanaman $(\mathrm{cm})$} \\
\cline { 2 - 4 } & $15 \mathrm{HST}$ & $30 \mathrm{HST}$ & $45 \mathrm{HST}$ \\
\hline AB Mix (N1) & $10,05 \mathrm{a}$ & $19,06 \mathrm{a}$ & $21,89 \mathrm{a}$ \\
POC Biogan (N2) & $8,52 \mathrm{~b}$ & $14,63 \mathrm{~b}$ & $19,60 \mathrm{~b}$ \\
POP Supernasa (N3) & $7,44 \mathrm{c}$ & $14,41 \mathrm{~b}$ & $18,45 \mathrm{c}$ \\
\hline
\end{tabular}

Keterangan: Rerata yang diikuti huruf yang sama pada kolom yang sama menunjukkan berbeda tidak nyata pada uji DMRT taraf 5\%.

Tabel 1. Menunjukkan bahwa variabel tinggi tanaman semua umur tanaman dipengaruhi oleh perlakuan nutrisi. perlakuan nutrisi $\mathrm{AB}$ Mix cenderung bertambah tinggi. Menurut Fitriansah $d k k$ (2019), pertumbuhan tinggi tanaman terjadi akibat dari pemanjangan dan pertambahan ruas pada batang. Pemanjangan ruas terjadi karena aktivitas pembelahan sel yang menyebabkan pertambahan jumlah sel.

Tabel 2. Rerata tinggi tanaman yang dipengaruhi oleh perlakuan varietas semua umur tanaman.

\begin{tabular}{lccc}
\hline \multirow{2}{*}{\multicolumn{1}{c}{ Varietas }} & \multicolumn{3}{c}{ Tinggi tanaman $(\mathrm{cm})$} \\
\cline { 2 - 4 } & $15 \mathrm{HST}$ & $30 \mathrm{HST}$ & $45 \mathrm{HST}$ \\
\hline Selada keriting (V1) & $9,10 \mathrm{a}$ & $17,37 \mathrm{a}$ & $20,88 \mathrm{a}$ \\
Selada merah (V2) & $7,93 \mathrm{~b}$ & $14,21 \mathrm{~b}$ & $18,41 \mathrm{~b}$ \\
Selada krop (V3) & $8,98 \mathrm{a}$ & $16,52 \mathrm{c}$ & $20,65 \mathrm{a}$ \\
\hline
\end{tabular}

Keterangan: Rerata yang diikuti huruf yang sama pada kolom yang sama menunjukkan berbeda tidak nyata pada uji DMRT taraf $5 \%$.

Tabel 2. Menunjukkan bahwa variabel tinggi tanaman semua umur tanaman dipengaruhi oleh perlakuan varietas. Menurut Duaja (2012), tanaman setiap waktu terus tumbuh yang menunjukkan telah terjadi pembelahan dan pembesaran sel dan pertumbuhan tanaman sangat dipengaruhi oleh lingkungan.

\section{Jumlah daun}

Tabel 3. Rerata jumlah daun yang dipengaruhi oleh perlakuan nutrisi pada umur 15 dan 45 hst.

\begin{tabular}{lcc}
\hline \multirow{2}{*}{ Nutrisi } & \multicolumn{2}{c}{ Jumlah daun } \\
\cline { 2 - 3 } & $15 \mathrm{HST}$ & $45 \mathrm{HST}$ \\
\hline AB Mix (N1) & $4,37 \mathrm{a}$ & $12,11 \mathrm{a}$ \\
POC Biogan (N2) & $3,11 \mathrm{~b}$ & $10,78 \mathrm{~b}$ \\
POP Supernasa (N3) & $3,00 \mathrm{~b}$ & $10,85 \mathrm{~b}$ \\
\hline
\end{tabular}

Keterangan: Rerata yang diikuti huruf yang sama pada kolom yang sama menunjukkan berbeda tidak nyata pada uji DMRT taraf 5\%. 
Tabel 3. Menunjukkan bahwa variabel jumlah daun berumur 15 dan 45 hst dipengaruhi oleh perlakuan nutrisi. Menurut Prastowo dan Patola (2013), tersedianya unsur nitrogen dalam jumlah yang cukup maka direspon secara maksimum oleh tanaman selada untuk membentuk protoplasma dalam jumlah yang banyak.

Tabel 4. Rerata jumlah daun yang dipengaruhi oleh perlakuan varietas pada umur 30 dan 45 hst.

\begin{tabular}{lcc}
\hline \multirow{2}{*}{ Varietas } & \multicolumn{2}{c}{ Jumlah daun } \\
\cline { 2 - 3 } & $30 \mathrm{HST}$ & $45 \mathrm{HST}$ \\
\hline Selada keriting (V1) & $6,48 \mathrm{a}$ & $12,19 \mathrm{a}$ \\
Selada merah (V2) & $5,22 \mathrm{~b}$ & $9,96 \mathrm{~b}$ \\
Selada krop (V3) & $6,19 \mathrm{a}$ & $11,59 \mathrm{c}$ \\
\hline
\end{tabular}

Keterangan: Rerata yang diikuti huruf yang sama pada kolom yang sama menunjukkan berbeda tidak nyata pada uji DMRT taraf 5\%.

Tabel 4. Menunjukkan bahwa variabel jumlah daun pada umur 30 dan 45 hst yang dipengaruhi oleh perlakuan varietas. Menurut Siregar (2018), tanaman yang memiliki kandungan klorofil yang tinggi disebabkan pemberian nutrisi yang cukup sehingga meningkatkan jumlah daun.

Tabel 5. Rerata interaksi nutrisi dan varietas pada variabel pengamatan jumlah daun 30 hst.

\begin{tabular}{lccc}
\hline \multirow{2}{*}{\multicolumn{1}{c}{ Nutrisi }} & \multicolumn{3}{c}{ Varietas } \\
\cline { 2 - 4 } & $\mathrm{V} 1$ & $\mathrm{~V} 2$ & $\mathrm{~V} 3$ \\
\hline AB Mix (N1) & $20,0 \mathrm{aA}$ & $17,0 \mathrm{bA}$ & $21,3 \mathrm{aA}$ \\
POC Biogan (N2) & $19,3 \mathrm{aB}$ & $15,6 \mathrm{bB}$ & $15,0 \mathrm{bB}$ \\
POP Supernasa (N3) & $19,0 \mathrm{aB}$ & $14,3 \mathrm{bC}$ & $19,3 \mathrm{aC}$ \\
\hline
\end{tabular}

Keterangan: Rerata yang diikuti huruf $(a, b, c)$ yang sama pada baris yang sama menunjukkan berbeda tidak nyata, rerata yang diikuti huruf $(A, B, C)$ yang sama pada kolom yang sama menunjukkan berbeda tidak nyata pada uji DMRT taraf 5\%.

Adapun interaksi jumlah daun umur 30 hst baris pertama menunjukkan bahwa perlakuan nutrisi AB Mix dalam varietas selada merah (N1V2) berbeda nyata dengan interaksi nutrisi $A B$ Mix dalam varietas selada keriting (N1V1) dan interaksi nutrisi AB mix dalam varietas selada krop (N1V3). Namun interaksi nutrisi AB Mix dalam varietas selada keriting (N1V1) berbeda tidak nyata dengan interaksi nutrisi AB Mix dalam varietas selada krop (N1V3) dengan rerata 19. Baris kedua perlakuan interaksi nutrisi POC Biogan dalam varietas selada keriting (N2V1) berbeda nyata dengan interaksi nutrisi POC Biogan dalam varietas selada merah (N2V2) dan interaksi nutrisi POC Biogan dalam varietas selada krop (N2V3) dengan rerata 17. Baris ketiga perlakuan interaksi nutrisi POP Supernasa dalam varietas selada merah (N3V2) berbeda nyata dengan interaksi nutrisi POP Supernasa dalam varietas selada keriting (N3V1) dan interaksi nutrisi POP Supernasa dalam varietas selada krop (N3V3) namun interaksi nutrisi POP 
Supernasa dalam varietas selada keriting (N3V1) berbeda tidak nyata dengan interaksi nutrisi POP Supernasa dalam varietas selada krop (N3V3) dengan rerata 26.

Pada kolom pertama perlakuan interaksi nutrisi AB Mix dalam varietas selada keriting (N1V1) berbeda nyata dengan interaksi nutrisi POC Biogan dalam varietas selada keriting (N2V1) dan interaksi nutrisi POP Supernasa dalam varietas selada keriting (N3V1) namun interaksi nutrisi POC Biogan dalam varietas selada keriting (N2V1) berbeda tidak nyata dengan interaksi nutrisi POP Supernasa dalam varietas selada keriting (N3V1) dengan rerata 19. Kolom kedua interaksi nutrisi AB Mix dalam varietas selada merah (N1V2), interaksi nutrisi POC Biogan dalam varietas selada merah (N2V2), interaksi nutrisi POP Supernasa dalam varietas selada merah (N3V2) ketiganya menunjukkan perlakuan berbeda nyata dengan rerata 16. Kolom ketiga interaksi nutrisi nutrisi AB Mix dalam varietas selada krop (N1V3), interaksi nutrisi POC Biogan dalam varietas selada krop (N2V3), interaksi nutrisi POP Supernasa dalam varietas selada krop (N3V3) ketiganya menunjukkan perlakuan berbeda nyata dengan rerata 18 . Hal ini diduga unsur hara yang terkandung di dalam AB Mix yaitu unsur nitrogen yang berperan dalam pembentukan daun. Berdasarkan penelitian Purwanto dkk (2019), penggunaan nutrisi AB Mix dapat menghasilkan jumlah daun maksimal karena unsur nitrogen yang terkandung didalam nutrisi $\mathrm{AB}$ Mix lebih lengkap dan mencukupi kebutuhan tanaman selada dibanding pupuk organik.

\section{Lebar daun}

Tabel 6. Rerata lebar daun yang dipengaruhi oleh perlakuan nutrisi semua umur tanaman.

\begin{tabular}{lccc}
\hline \multirow{2}{*}{ Nutrisi } & \multicolumn{3}{c}{ Lebar daun (cm) } \\
\cline { 2 - 4 } & $15 \mathrm{HST}$ & $30 \mathrm{HST}$ & $45 \mathrm{HST}$ \\
\hline AB Mix (N1) & $6,08 \mathrm{a}$ & $12,80 \mathrm{a}$ & $15,79 \mathrm{a}$ \\
POC Biogan (N2) & $5,01 \mathrm{~b}$ & $11,17 \mathrm{~b}$ & $14,09 \mathrm{~b}$ \\
POP Supernasa (N3) & $3,98 \mathrm{c}$ & $11,43 \mathrm{~b}$ & $13,07 \mathrm{c}$ \\
\hline
\end{tabular}

Keterangan: Rerata yang diikuti huruf yang sama pada kolom yang sama menunjukkan berbeda tidak nyata pada uji DMRT taraf 5\%.

Tabel 6. Menunjukkan bahwa variabel lebar daun pada semua umur tanaman yang dipengaruhi oleh perlakuan nutrisi. Unsur nitrogen yang tersedia cukup mempengaruhi daun lebih hijau dan proses fotosintesis berjalan lebih besar sehingga laju fotosintesis lalu daun menerima dan menyerap cahaya matahari lebih tinggi sehingga fotosintat dan energi yang dihasilkan tinggi pula (Puspita $d k k, 2016$ ). 
Tabel 7. Rerata lebar daun yang dipengaruhi oleh perlakuan varietas pada umur 30 dan 45 hst.

\begin{tabular}{ccc}
\hline Varietas & \multicolumn{2}{c}{ Lebar daun (cm) } \\
\cline { 2 - 3 } & $30 \mathrm{HST}$ & $45 \mathrm{HST}$ \\
\hline Selada keriting (V1) & $11,51 \mathrm{~b}$ & $14,37 \mathrm{a}$ \\
Selada merah (V2) & $11,42 \mathrm{~b}$ & $13,31 \mathrm{~b}$ \\
Selada krop (V3) & $12,47 \mathrm{a}$ & $15,25 \mathrm{c}$ \\
\hline
\end{tabular}

Keterangan: Rerata yang diikuti huruf yang sama pada kolom yang sama menunjukkan berbeda tidak nyata pada uji DMRT taraf 5\%.

Tabel 7. Menunjukkan bahwa variabel lebar daun pada umur 30 dan 45 hst yang dipengaruhi oleh perlakuan varietas. Menurut Wardhani (2019), lebar daun sangat dipengaruhi oleh jumlah air yang diserap oleh tanaman. Bagi tanaman, air berfungsi sebagai pelarut unsur hara dan transportasi unsur hara dari akar ke seluruh bagian tanaman.

Tabel 8. Rerata interaksi nutrisi dan varietas pada variabel pengamatan jumlah daun 30 hst.

\begin{tabular}{lccc}
\hline \multicolumn{1}{c}{ Nutrisi } & V1 & V2 & V3 \\
\hline AB Mix (N1) & $37,4 \mathrm{bA}$ & $35,7 \mathrm{bA}$ & $42,0 \mathrm{aA}$ \\
POC Biogan (N2) & $32,5 \mathrm{bB}$ & $33,0 \mathrm{bB}$ & $35,0 \mathrm{aB}$ \\
POP Supernasa (N3) & $33,7 \mathrm{aB}$ & $33,9 \mathrm{aB}$ & $35,2 \mathrm{aB}$ \\
\hline
\end{tabular}

Keterangan: Rerata yang diikuti huruf $(a, b, c)$ yang sama pada baris yang sama menunjukkan berbeda tidak nyata, rerata yang diikuti huruf $(A, B, C)$ yang sama pada kolom yang sama menunjukkan berbeda tidak nyata pada uji DMRT taraf 5\%.

Adapun interaksi lebar daun umur 30 hst baris pertama menunjukkan bahwa perlakuan nutrisi $A B$ Mix dalam varietas selada krop (N1V3) berbeda nyata dengan interaksi nutrisi $A B$ Mix dalam varietas selada merah (N1V2) dan interaksi nutrisi AB Mix dalam varietas selada keriting (N1V1). Interaksi nutrisi AB Mix dalam varietas selada merah (N1V2) berbeda tidak nyata dengan interaksi nutrisi AB Mix dalam varietas selada keriting (N1V1) dengan rerata 38. Baris kedua interaksi nutrisi POC Biogan dalam varietas selada krop (N2V3) berbeda nyata dengan interaksi nutrisi POC Biogan dalam varietas selada merah (N2V2) dan interaksi nutrisi POC dalam varietas selada keriting (N2V1). Interaksi nutrisi POC Biogan dalam varietas selada merah (N2V2) berbeda tidak nyata dengan interaksi nutrisi POC Biogan dalam varietas selada keriting (N2V1) dengan rerata 33. Baris ketiga interaksi POP Supernasa dalam varietas selada keriting (N3V1), interaksi nutrisi POP Supernasa dalam varietas selada merah (N3V2) dan interaksi nutrisi POP Supernasa dalam varietas selada krop (N3V3) ketiga perlakuan menunjukkan berbeda tidak nyata dengan rerata 34.

Kolom pertama interaksi nutisi AB Mix dalam varietas selada keriting (N1V1) berbeda nyata dengan interaksi nutrisi POC Biogan dalam varietas selada keriting (N2V1), interaksi nutrisi POP Supernasa dalam varietas selada keriting (N3V1). interaksi nutrisi POC Biogan dalam varietas selada keriting $(\mathrm{N} 2 \mathrm{~V} 1)$ berbeda tidak nyata dengan interaksi nutrisi POP 
Supernasa dalam varietas selada keriting (N3V1) dengan rerata 34. Kolom kedua interaksi nutisi AB Mix dalam varietas selada merah (N1V2) berbeda nyata dengan interaksi nutrisi POC Biogan dalam varietas selada merah (N2V2), interaksi nutrisi POP Supernasa dalam varietas selada merah (N3V2). interaksi nutrisi POC Biogan dalam varietas selada merah (N2V2) berbeda tidak nyata dengan interaksi nutrisi POP Supernasa dalam varietas selada merah (N3V2) dengan rerata 34. Kolom ketiga interaksi nutisi AB Mix dalam varietas selada krop (N1V3) berbeda nyata dengan interaksi nutrisi POC Biogan dalam varietas selada krop (N2V3), interaksi nutrisi POP Supernasa dalam varietas selada krop (N3V3). interaksi nutrisi POC Biogan dalam varietas selada krop (N2V3) berbeda tidak nyata dengan interaksi nutrisi POP Supernasa dalam varietas selada krop (N3V3) dengan rerata 37. Hal ini diduga karena kandungan unsur hara larutan AB Mix mencukupi kebutuhan tanaman sayuran sehingga mudah diserap oleh tanaman dibanding dengan pupuk organik. Hal ini diperkuat oleh Rahmawati \& Widyasunu (2013), pupuk organik memiliki cara kerja yang lambat karena mengalami proses dekomposisi dan mineralisasi terlebih dahulu sebelum diserap oleh akar tanaman.

\section{Panjang daun}

Tabel 9. Rerata panjang daun yang dipengaruhi oleh perlakuan nutrisi semua umur tanaman

\begin{tabular}{lccc}
\hline \multirow{2}{*}{ Nutrisi } & \multicolumn{3}{c}{ Panjang daun (cm) } \\
\cline { 2 - 4 } & $15 \mathrm{HST}$ & $30 \mathrm{HST}$ & $45 \mathrm{HST}$ \\
\hline AB Mix (N1) & $7,09 \mathrm{a}$ & $14,86 \mathrm{a}$ & $17,42 \mathrm{a}$ \\
POC Biogan (N2) & $6,04 \mathrm{~b}$ & $12,47 \mathrm{~b}$ & $14,89 \mathrm{~b}$ \\
POP Supernasa (N3) & $5,55 \mathrm{~b}$ & $12,09 \mathrm{~b}$ & $13,93 \mathrm{c}$
\end{tabular}

Keterangan: Rerata yang diikuti huruf yang sama pada kolom yang sama menunjukkan berbeda tidak nyata pada uji DMRT taraf 5\%.

Tabel 9. Menunjukkan bahwa variabel panjang daun pada semua umur tanaman yang dipengaruhi oleh perlakuan nutrisi. Menurut Lingga (2005), kandungan hara nitrogen dan phospor pada pupuk AB Mix mempunyai peran untuk merangsang pertumbuhan tanaman secara keseluruhan seperti batang, cabang dan daun.

Tabel 10. Rerata panjang daun yang dipengaruhi oleh perlakuan varietas pada umur 30 dan 45 hst.

\begin{tabular}{lcc}
\hline \multirow{2}{*}{ Varietas } & \multicolumn{2}{c}{ Panjang daun (cm) } \\
\cline { 2 - 3 } & $30 \mathrm{HST}$ & $45 \mathrm{HST}$ \\
\hline Selada keriting (V1) & $13,19 \mathrm{a}$ & $15,58 \mathrm{a}$ \\
Selada merah (V2) & $12,18 \mathrm{~b}$ & $14,20 \mathrm{~b}$ \\
Selada krop (V3) & $14,05 \mathrm{c}$ & $16,46 \mathrm{c}$ \\
\hline
\end{tabular}

Keterangan: Rerata yang diikuti huruf yang sama pada kolom yang sama menunjukkan berbeda tidak nyata pada uji DMRT taraf 5\%. 
Tabel 10. Menunjukkan bahwa variabel panjang daun pada umur 30 dan 45 hst yang dipengaruhi oleh perlakuan varietas. Menurut Fitrianah $d k k$ (2012), terjadinya panjang tanaman dari pertumbuhan tanaman menyebabkan perpanjangan ruas-ruas tanaman yang disebabkan oleh memanjang dan membersarnya sel-sel. Pertambahan sel dipengaruhi oleh bertambahnya umur tanaman dan tersedianya unsur hara makro seperti nitrogen dalam pertumbuhan vegetatif.

\section{Panjang akar}

Tabel 11. Rerata panjang akar yang dipengaruhi oleh perlakuan nutrisi.

\begin{tabular}{lc}
\hline \multicolumn{1}{c}{ Nutrisi } & Panjang akar (cm) \\
\hline AB Mix (N1) & $16,57 \mathrm{a}$ \\
POC Biogan (N2) & $13,89 \mathrm{~b}$ \\
POP Supernasa (N3) & $12,97 \mathrm{~b}$ \\
\hline
\end{tabular}

Keterangan: Rerata yang diikuti huruf yang sama menunjukkan berbeda tidak nyata pada uji DMRT taraf 5\%.

Tabel 11. Menunjukkan bahwa variabel panjang akar yang dipengaruhi oleh perlakuan nutrisi. Menurut Qalyubi (2014), fosfor memiliki peranan penting pada tanaman yaitu mendorong pertumbuhan akar sehingga proses penyerapan unsur hara dari larutan menuju tanaman berjalan dengan lancar.

\section{Berat segar akar}

Tabel 12. Rerata berat segar akar yang dipengaruhi oleh perlakuan nutrisi.

\begin{tabular}{lc}
\hline \multicolumn{1}{c}{ Nutrisi } & Berat segar akar (gr) \\
\hline AB Mix (N1) & $11,33 \mathrm{a}$ \\
POC Biogan (N2) & $7,41 \mathrm{~b}$ \\
POP Supernasa (N3) & $8,52 \mathrm{~b}$ \\
\hline
\end{tabular}

Keterangan: Rerata yang diikuti huruf yang sama menunjukkan berbeda tidak nyata pada uji DMRT taraf 5\%.

Tabel 12. Menunjukkan bahwa variabel berat segar akar yang dipengaruhi oleh perlakuan nutrisi. Berdasarkan penelitian Sumaryani \& Ari (2016), pupuk paling baik bagi pertumbuhan tanaman selada keriting adalah pupuk AB mix karena pupuk AB mix memiliki unsur-unsur yang lengkap untuk memenuhi kebutuhan nutrisi tanaman selada kerting. Unsur-unsur yang dimiliki pupuk $\mathrm{AB}$ mix yaitu unsur hara makro yaitu: $\mathrm{N}, \mathrm{P}, \mathrm{K}, \mathrm{Ca}, \mathrm{Mg}, \mathrm{S}$, unsur mikro yaitu : Fe, Mn, Bo, $\mathrm{Zn}, \mathrm{Cu}, \mathrm{Mo}$. 
Agritrop, Vol. 18 (2): $151-161$

\section{Berat segar tanaman}

Tabel 13.Rerata berat segar tanaman yang dipengaruhi oleh perlakuan nutrisi.

\begin{tabular}{lc}
\hline \multicolumn{1}{c}{ Nutrisi } & Berat segar tanaman (gr) \\
\hline AB Mix (N1) & $62,41 \mathrm{a}$ \\
POC Biogan (N2) & $40,26 \mathrm{~b}$ \\
POP Supernasa (N3) & $39,15 \mathrm{~b}$ \\
\hline
\end{tabular}

Keterangan: Rerata yang diikuti huruf yang sama menunjukkan berbeda tidak nyata pada uji DMRT taraf 5\%.

Tabel 13. Menunjukkan bahwa variabel berat segar tanaman yang dipengaruhi oleh perlakuan nutrisi. Menurut Asprillia $d k k$ (2018), meningkatnya berat tanaman yang dikonsumsi dikarenakan semakin banyak pula jumlah klorofil yang dapat memperlancar fotosintesis sehingga meningkatkan cadangan makanan untuk disimpan dan dapat mempengaruhi berat tanaman yang dikonsumsi.

Tabel 14. Rerata berat segar tanaman yang dipengaruhi oleh perlakuan varietas

\begin{tabular}{lc}
\hline \multicolumn{1}{c}{ Varietas } & Berat segar tanaman (gr) \\
\hline Selada keriting (V1) & $49,41 \mathrm{a}$ \\
Selada merah (V2) & $37,48 \mathrm{~b}$ \\
Selada krop (V3) & $54,93 \mathrm{c}$ \\
\hline
\end{tabular}

Keterangan: Rerata yang diikuti huruf yang sama menunjukkan berbeda tidak nyata pada uji DMRT taraf 5\%.

Tabel 14. Menunjukkan bahwa variabel berat segar tanaman yang dipengaruhi oleh perlakuan varietas. Daun merupakan tepat terjadinya fotosintesis, jika fotosintesis berjalan dengan baik maka fotosintat yang dihasilkan juga banyak. Hasil fotosintat akan digunakan untuk pembentukan organ dan jaringan dalam tanaman seperti daun sehingga berat segar tanaman akan meningkat (Wulandari \& Harjoko, 2017).

\section{KESIMPULAN}

Berdasarkan hasil penelitian Varietas Selada (Lactuca sativa L.) Terhadap Sumber Nutrisi pada Sistem Hidroponik, dapat disimpulkan bahwa:

1. Perlakuan varietas menunjukkan varietas selada krop (V3) merupakan varietas terbaik karena berpengaruh terhadap lebar daun, panjang daun semua umur tanaman, berat segar akar dan berat segar tanaman.

2. Perlakuan nutrisi AB mix merupakan perlakuan nutrisi terbaik karena berpengaruh terhadap pertumbuhan tanaman selada.

3. Interaksi antar nutrisi dengan varietas memberikan berpengaruh terhadap jumlah daun 30 hst dan lebar daun 30 hst. 


\section{DAFTAR PUSTAKA}

Asprillia, S. V., Darmawati, A., dan Slamet, W. 2018. Pertumbuhan Produksi Selada (Lactuca sativa L.) pada Pemberian Berbagai Jenis Pupuk Organik. Journal Of Agro Complex. 2(1). 86-92.

Badan Pusat Statistik. 2015. Kepadatan penduduk menurut provinsi 2000-2015.Jakarta pusat : Badan Pusat Statistik.

Badan Pusat Statistik. 2017. Produksi Tanaman Selada di Indonesia Tahun 2014-2017. Jakarta Pusat : Badan Pusat Statistik.

Duaja, M. D. 2012. Pengaruh Bahan Dan Dosis Kompos Cair Terhadap Pertumbuhan Selada (Lactuca sativa sp.) (The Effect Of Material And Dosages Of Liquid Organic Fertilizers On Lettuce (Lactuca sativa sp.) Growth). Bioplantae. 1(1).

Fitrianah, L., Fatimah, S., dan Hidayati, Y. 2012. Pengaruh Komposisi Media Tanam Pertumbuhan dan Kandungan Saponin pada Dua Varietas Tanaman Gendola (Basella sp.). Agrovigor: Jurnal Agroekoteknologi, 5(1). 34-46.

Fitriansah, T., Roviq, M., dan Karyawati, A. S.2019. Pertumbuhan Tanaman Selada (Lactuca Sativa L.) pada Dosis dan Interval Penambahan Ab Mix Dengan Sistem Hidroponik. Jurnal Produksi Tanaman.7(3).

Lingga, P. 2006. Hidroponik Bercocok Tanam Tanpa Tanah. Jakarta : Penebar Swadaya.

Rahmawati, E., dan Widyasunu, P. 2013. Pengaruh Bokashi Berbasis Azolla Microphylla dan lemma polyrhiza terhadap Serapan N dan Produksi tanaman pakchoy (Brassica chinensis L.) serta porositas inseptisols. Agrin, 17(2).

Roidah, I. S. 2015. Pemanfaatan Lahan dengan Menggunakan Sistem Hidroponik. Jurnal bonorowo, 1(2), 43-49.

Suhandoko, A. A., Sumarsono, S., \& Purbajanti, E. D. 2018. Produksi selada (Lactuca sativa L.) dengan penyinaran lampu led merah dan biru di malam hari pada teknologi hidroponik sistem terapung termodifikasi. Journal Of Agro Complex, 2(1), 79-85.

Prastowo, B., dan Patola, E. 2013. Pengaruh Cara Penanaman Dan Dosis Pupuk Urea Terhadap Pertumbuhan dan Hasil Tanaman Selada Daun (Lactuca Sativa L.) The Influence Of Cultivation Method and The Dosage Of Fertilizer Urea To Growth And Yield Of Lead Lettuce Crop. INNOFARM : Jurnal Inovasi Pertanian Vol. 12, No.2.

Purwanto, E., Sunaryo, Y., dan Widata, S. 2019. Pengaruh Kombinasi Pupuk AB Mix dan Pupuk Organik Cair (POC) Kotoran Kambing terhadap Pertumbuhan dan Hasil Sawi (Brassica juncea L.) Hidroponik. Jurnal Ilmiah Agroust. 2(1), 11-24. 
Puspita Sari. R., M, Maghfoer, M. D,. dan Koesriharti, K. 2016. Pengaruh Frekuensi Penyiraman dan Dosisi Pupuk Kandang Ayam terhadap pertumbuhan dan hasil tanaman pakcoy (Brassica rapa L. var. Chinensis). Jurnal Produksi Tanaman. 4(5).342-351.

Qalyubi, I. 2014. Pengaruh Debit Air dan Pemberian Jenis Nutrisi terhadap Pertumbuhan Tanaman Kangkung pada Sistem Irigasi Hidroponik NFT (Nutrient Film Tehnique). Skripsi. Universitas Negeri Jember.

Siregar, M. 2018. Respon Pemberian Nutrisi AB Mix Pada Sistem Tanam Hidroponik Terhadap Pertumbuhan dan Produksi Tanaman Sawi (Brassica Juncea). Jasa Padi. 2(02). 18-24.

Sumaryani, N. P, dan Ari, G. W. 2016. Pengaruh Pemberian Pupuk NPK, AB Mix, dan Pupuk Kompos Cair Melalui Media Tanam Aeroponik Terhadap Pertumbuhan Tanaman Selada Keriting (Lactuca sativa L.). Emasains : Jurnal Edukasi Matematika dan Sains. 5(2), 4655.

Wardhani, A. T. 2019. Uji Pertumbuhan dan Produksi Tanaman Sawi Keriting (Brassica juncea L.) secara Hidroponik dengan Sumber Nutrisi yang berbeda. Skripsi. Universitas medan area.

Wulandari, S., dan Harjoko, D. 2017. Pertumbuhan Selada Dalam Hidroponik Substrat Dengan Perbedaan Ukuran Serat Aren dan Nutrisi. In Prosiding Seminar Nasional Fakultas UNS. Vol 1, No. 1, pp. 165-172. 